\title{
Numerical Study of Precipitation Intensification and Ice-Phase Microphysical Processes in Typhoon Spiral Band
}

\author{
Mitsuharu NOMURA \\ Hydrospheric Atmospheric Research Center Nagoya University, Nagoya, Japan \\ and \\ Kazuhisa TSUBOKI \\ Hydrospheric Atmospheric Research Center Nagoya University, Nagoya, Japan \\ Frontier Research Center for Global Change, Yokohama, Japan
}

(Manuscript received 15 September 2011, in final form 2 February 2012)

\begin{abstract}
Spiral bands are characteristic meso-beta-scale structures of typhoons in their mature stages. Observational study shows that spiral bands cause strong rainfall. The spiral bands are classified into two types: inner and outer rainbands. The inner rainband is formed near the typhoon center. In this study, we focus on the precipitation process in the inner rainband within the typhoon. Two neighboring spiral bands are often observed near the typhoon center. Previous studies have shown the mechanism of intensifying rainfall in the inner-side spiral band of two neighboring inner rainbands that frequently form in this region. However, the intensification of the outer-side spiral band of two neighboring inner rainbands has not been widely reported. Therefore, to clarify the mechanism of intensifying rainfall in the spiral bands, we focus on cloud microphysical processes and perform a numerical experiment using a cloud-resolving model. We show that cold rain processes are important for the intensification of precipitation in the spiral band. In particular, production and growth of graupel are the most effective processes for the intensification of precipitation in the spiral band.
\end{abstract}

\section{Introduction}

Spiral bands are characteristic structures of typhoons that bring strong rainfall in their mature stages. Spiral bands are classified into two categories: inner and outer rainbands. The former forms near the typhoon center and the latter develops hundreds of kilometers or more from the center. Strong rainfall is generated near the typhoon center because it contains several inner bands. In the present study, we focus on the precipitation

Corresponding author and present affiliation: Mitsuharu Nomura, Central Research Institute of Electric Power Industry, 1646 Abiko, Abiko-Shi, Chiba 270-1194, Japan E-mail: nomuharu@criepi.denken.or.jp

(C)2012, Meteorological Society of Japan process in the inner rainband.

Detailed studies on spiral bands began with the use of radars after World War II. In early research, a simple structure of the spiral band, the motion of convective cells in the band, and the relationship between radar reflectivity and ground observation data were revealed using ground-based radar (e.g., Senn and Hiser 1959; Staff Members, Tokyo University, 1969). In other studies, airborne radar was employed (e.g., Simpson and Starrrett 1955; Jorgensen 1984; Willoughby et al. 1984; Powell 1990). Powell (1990) observed the rainbands of three hurricanes by aircraft and showed that the width of the outer rainband was $15-20 \mathrm{~km}$ and the time scale of the convective cell generation in the spiral band was 15-30 minutes. In addition, a cell in 
the rainband was shown to lean toward the outside of the hurricane towering up to an altitude of 7-9 km.

On the other hand, Willoughby et al. (1984) studied the inner rainband that formed near the hurricane center. They exhibited that strong rainfall within the hurricane occurred in the eyewall and the stationary band complex (SBC) defined as the rainband united with two spiral bands near the hurricane center. However, this study did not show the cloud and precipitation processes in the spiral band. Shibagaki et al. (2003) observed the inner band and the eyewall after typhoon landfall using the middle and upper atmosphere radar, finding wide and narrow rainbands. The wide rainband was located along the outer edge of the upper-level band-shaped cloud and was accompanied by a tilted outflow region. The narrow rainband had a short lifetime and was accompanied by the tilted outflow region in its convective portion. They also suggested that upper-level clouds contributed to the formation and maintenance of stratiform precipitation by the seeder-feeder mechanism. Heymsfield et al. (2006) studied cloud microphysical processes within the tropical cyclone inner region and determined particle image information and particle size distributions in the eyewall and near the eye regions of Tropical Storm/Hurricane Humberto using airborne single- and dual-wavelength Doppler radar. They found that high concentrations of small ice particles and aggregates of large particles were present in and around the updraft region in the eyewall. In addition, graupel was observed in the developed inner rainbands. Their study showed that large rain drops and graupel were generated by the aggregation process.

Although many observations have been conducted on outer and inner rainbands, they have not completely explained the structure and the precipitation process of the spiral band in the life cycle, including the stages of formation, development, maintenance, and decay because the observation period of airborne radars is limited. Using the ground radar as Shibagaki et al. (2003), it is difficult to understand the structure and the precipitation process of the spiral band without the influences of the terrain and land-surface. Moreover, detailed physical processes of precipitation in the spiral band, particularly the cloud microphysical processes in the mature stages over the ocean, have not been studied.

As Willoughby et al. (1984) and Shimazu (1998) showed, some spiral bands form near the center of hurricanes and typhoons, and two neighboring spiral bands are often observed. Willoughby et al. (1984) reported that strong rainfall was caused by the formation of the SBC. On the other hand, when the SBC was not formed, precipitation in the inner-side spiral band was intensified. Previous studies have shown a mechanism of increasing precipitation in the inner-side band between two spiral bands located near the typhoon center (May, 1996). The low-level inflow from outside the inner-side band deepened due to a decaying outerside band, and thus the convection in the inner-side band was intensified. As a result, precipitation intensified as condensation increased in the band. However, the mechanism of intensified precipitation in the outerside band has not been extensively researched.

Using a numerical model, the mesoscale convective system (MCS) and convective cloud in the typhoon spiral band were studied by Yamasaki (1986), Nasuno and Yamasaki (1997), Nasuno and Yamasaki (2001), and others. Yamasaki (1986) used a three-dimensional model to show that a spiral band formed with the cyclonic movement of the MCS generated by cold pool and warm moist air from the outer side of the typhoon at low level. However, this study did not show the detailed structure and intensifying precipitation process in the spiral band because warm rain parameterization and a horizontal resolution of $20 \mathrm{~km}$ were used. Using an axisymmetric model with a fine mesh, Nasuno and Yamasaki (1997) and Nasuno and Yamasaki (2001) showed that the new MCS periodically appeared outside an old MCS when the wind speed increased to some degree near the MCS. A new MCS cloud was successively generated by the outflow caused by the cold downdraft of the old MCS cloud and the inflow toward the typhoon center. These studies clarified the generation and development of convective clouds in the spiral band, the formation process of the spiral band, and the formation dynamics of the spiral band.

Liu et al. (1997) used a three-dimensional numerical model with a cold rain process to study the hurricane's inner core structure and its dynamics. However, the presence of cumulonimbus clouds within the hurricane was not resolved because the horizontal resolution was $6 \mathrm{~km}$. For resolving the detailed three-dimensional typhoon structure, especially the mesoscale structure and the precipitation process within the spiral band, a horizontal resolution of at least $1-2 \mathrm{~km}$ is necessary. Previous studies have shown the formation process and mechanism of the spiral band and the dynamics of the MCS clouds in the spiral band. However, these studies did not clarify the intensifying precipitation process in the spiral band and the intensifying mechanism of precipitation influenced by the interaction between two neighboring spiral bands, as shown by Willoughby et al. (1984). 
To understand the mechanism of intensification of precipitation in the spiral band, we investigate the principal physical process of intensifying precipitation with focusing on cloud microphysics by performing a numerical experiment of Typhoon SINLAKU (T0216) using a cloud-resolving model with fine grid spacing. This study aims to show the detailed cloud microphysical processes and the influences from the inner-side spiral band to the outer-side neighboring spiral band, as shown by Willoughby et al. (1984), to explain the mechanism of intensified precipitation in the spiral band.

\section{Model and experimental design}

\subsection{Model description}

The numerical model used in the present study is the Cloud Resolving Storm Simulator (CReSS: Tsuboki and Sakakibara 2002). CReSS is a three-dimensional cloud resolving numerical model formulated using a non-hydrostatic and compressible equation system with a bulk cold rain parameterization of cloud microphysics. Prognostic variables of water substances are mixing ratios of cloud water $\left(q_{c}\right)$, rain water $\left(q_{r}\right)$, cloud ice $\left(q_{i}\right)$, snow $\left(q_{s}\right)$, and graupel $\left(q_{g}\right)$, and the number concentrations of cloud ice, snow, and graupel. This model uses a 1.5-order closure with subgrid-scale turbulent kinetic energy and fourth order finite difference approximation in the advection term.

\subsection{Experimental design}

The initial data used in this experiment is the Regional Spectrum Model output at 0000 UTC, 4 September 2002 provided by the Japan Meteorological Agency (JMA-RSM). From the JMA-RSM data, Typhoon SINLAKU (T0216) in its mature stage was located near Okinawa Island, Japan (Fig. 1). At the initial time, the central pressure and the maximum wind speed of this typhoon were $960 \mathrm{hPa}$ and 38.6 $\mathrm{m} \mathrm{s}^{-1}$, respectively. Typhoon SINLAKU reached its most intense state with a central pressure of $955 \mathrm{hPa}$ and maximum wind speed of $41.2 \mathrm{~m} \mathrm{~s}^{-1}$ at 1200 UTC. Intensity of SINLAKU was maintained until 2100 UTC, 6 September 2002.

In order to understand the detailed structure and cloud microphysical processes in the spiral band, two numerical experiments were performed; the first experiment had a horizontal resolution of $5 \mathrm{~km}$ (CReSS-5 $\mathrm{km})$ and the other had a resolution of $2 \mathrm{~km}$ (CReSS-2 $\mathrm{km}$ ). CReSS $-5 \mathrm{~km}$ was calculated for a period of 24 hours from the initial time. This result was used only for the initial and boundary data of CReSS $-2 \mathrm{~km}$. In CReSS-2 km, the typhoon was simulated for 9 hours

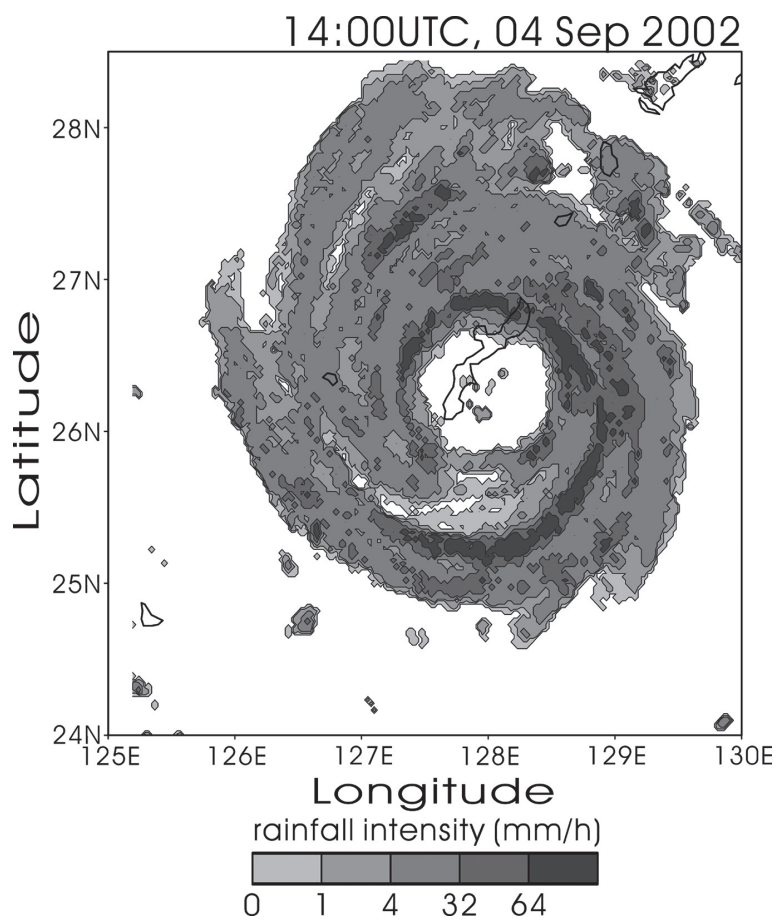

Fig. 1. Rainfall intensity derived from JMA radar at 1400 UTC, 4 September 2002.

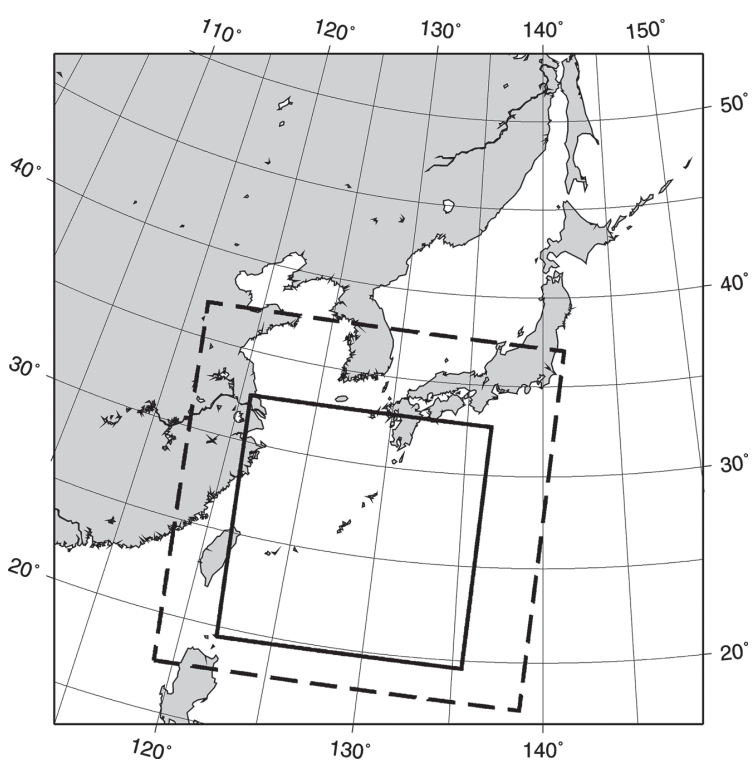

Fig. 2. Domains of CReSS-5km (dashed line) and CReSS-2km (solid line). 
from 1000 UTC using the CReSS-5km output. The calculation domains are shown in Fig. 2. The dashed line square is the domain of CReSS-5 km, and the solid line square is that of CReSS-2 $\mathrm{km}$. The vertical resolution in CReSS-5 $\mathrm{km}$ is stretched from $200 \mathrm{~m}$ at the lowest level to a height of $500 \mathrm{~m}$. In CReSS-2 km, the vertical grid is stretched from $100 \mathrm{~m}$ to $400 \mathrm{~m}$. We use the CReSS $-2 \mathrm{~km}$ outputs for all the analysis in the present study.

\section{Intensification of precipitation in spiral band}

The CReSS-2km results were examined to understand the detailed distribution of cloud (i.e., cloud water and cloud ice) and precipitation (i.e., rain water, snow, and graupel). The mixing ratio of cloud $\left(q_{C}\right)$ is the sum of $q_{c}$ and $q_{i}$. The mixing ratio of precipitation $\left(q_{p}\right)$ is the sum of $q_{r}, q_{s}$, and $q_{g}$. In the present study, a spiral band is defined as a rainband that has a length of several tens of kilometers and $q_{p}$ of $0.5 \mathrm{~g} \mathrm{~kg}^{-1}$ or more at a height of $2 \mathrm{~km}$. Figure 3 shows the distribution of $q_{p}$ and the wind field at a height of $2 \mathrm{~km}$ at 1400 UTC. Several spiral bands, indicated by arrows in Fig.3, were detected in the simulation. We compared the model result (Fig. 3) with the radar image (Fig. 1) and found that the concentration of $q_{p}$ in the spiral band and the width of the spiral band were successfully simulated. At that time, the precipitation intensity in the spiral band was strong.

At 1400 UTC, a decaying spiral band defined as Band-I was present at the inner side of the intensifying spiral band defined as Band-O (Fig. 4c). Band-I reached its mature stage at 1200 UTC and began to decay at 1300 UTC (Figs. 4a, b). At 1400 UTC, it decayed and precipitation weakened (Fig. 4c). On the other hand, Band-O was developing at 1300 UTC and reached its mature stage at 1400 UTC. Strong rainfall in Band-O was maintained until 1600 UTC (not shown). We focus on the intensified precipitation of Band-O and the decay of Band-I with the development of Band- $\mathrm{O}$.

Figure 5 shows the distribution of $q_{C}$ and $q_{p}$ at heights of 2 and $7 \mathrm{~km}$ at 1300 UTC when Band-O was in its developing stage. Band-I and Band-O produced large $q_{C}$ and $q_{p}$. In Band-O, large $q_{C}$ was distributed near the peak of $q_{p}$ (Fig. 5a). $q_{C}$ and $q_{p}$ in Band-I were smaller than those in Band-O. $q_{C}$ in Band-I was not concentrated, whereas that in Band-O was distributed sharply. As shown in Fig. $5 \mathrm{~b}, q_{p}$ at a height of $7 \mathrm{~km}$ was larger than that at a height of $2 \mathrm{~km}$. On the other hand, $q_{C}$ was less than that at a height of $2 \mathrm{~km}$. The width of the spiral band at a height of $7 \mathrm{~km}$ was broader than that at a height of $2 \mathrm{~km} . q_{s}$ was widely spread, and large

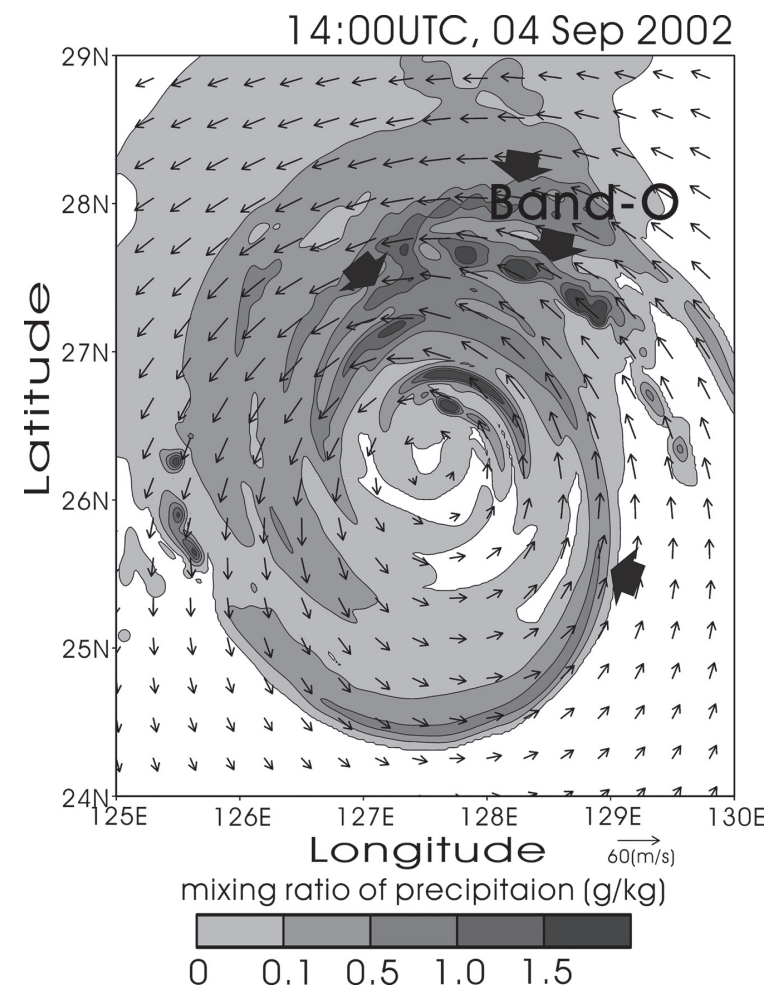

Fig. 3. $\quad q_{r}$ (shadings) and horizontal wind (vectors) at a height of $2 \mathrm{~km}$ at 1400 UTC. Thick arrows indicate spiral bands.

$q_{g}$ was present in the spiral band at a height of $7 \mathrm{~km}$ (Fig. 6). Above the rainfall region where $q_{p}$ was larger than $1.0 \mathrm{~g} \mathrm{~kg}^{-1}$ (Fig. 5a), particularly large $q_{g}$ was present. Although $q_{g}$ was small in decaying Band-I, it was larger in developing Band-O. On the other hand, $q_{s}$ was similar in both bands; however, it was smaller in the region where large $q_{g}$ was present.

Band-O tilted outward with height, and the width of the strong rainfall region was $10-20 \mathrm{~km}$ (Fig. 7). In Band-O, two peaks of $q_{p}$ were recorded above and below the $0^{\circ} \mathrm{C}$ level, which was located at an approximate height of $5.4 \mathrm{~km}$. The peak above the $0^{\circ} \mathrm{C}$ level was larger than that below it. $q_{C}$ was large in the spiral bands but small between the bands. A peak of $q_{C}$ was recorded in the innermost part of the axis of Band-O below the $0^{\circ} \mathrm{C}$ level (Figs. 5a, 7). Large $q_{p}$ was distributed in the outermost parts of Band-O. $q_{p}$ and $q_{C}$ in Band-I were smaller than those in other bands. In particular, above a height of $6 \mathrm{~km}, q_{C}$ was small, clearly the result of water vapor provided by a weak updraft from the lower level. In Band-O, the peak of $q_{p}$ was present at an approximate height of $7 \mathrm{~km}$, and $q_{C}$ 

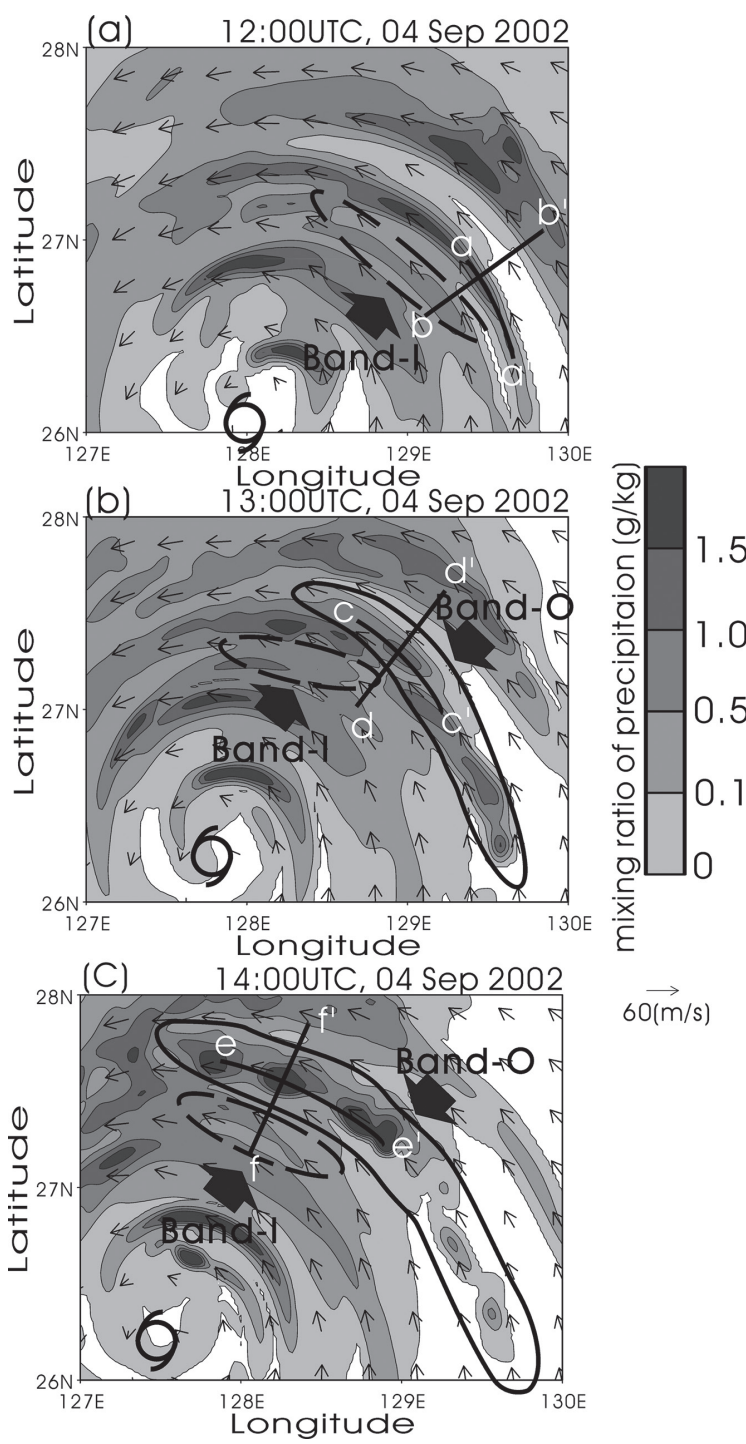

$60(\mathrm{~m} / \mathrm{s})$

Fig. 4. $q_{r}$ (shadings) and horizontal wind (vectors) at a height of $2 \mathrm{~km}$ at (a) $1200 \mathrm{UTC}$, (b) 1300 UTC, and (c) 1400 UTC.

was larger than that in other bands above the $0^{\circ} \mathrm{C}$ level. It appears that large $q_{C}$ was transported from the lower level because the updraft near the $0^{\circ} \mathrm{C}$ level is stronger than that around other heights.

To further clarify the detailed distribution of precipitation in the spiral band, we examined the vertical distribution of precipitation categories in the spiral band (Fig. 8). In Band-O, $q_{g}$ was $2.0 \mathrm{~g} \mathrm{~kg}^{-1} . q_{s}$ in the inner side of the axis of Band-O was larger than that in its outer side. In particular, the peak of $q_{s}$ was present between Band-I and Band-O. Above the strong rain-

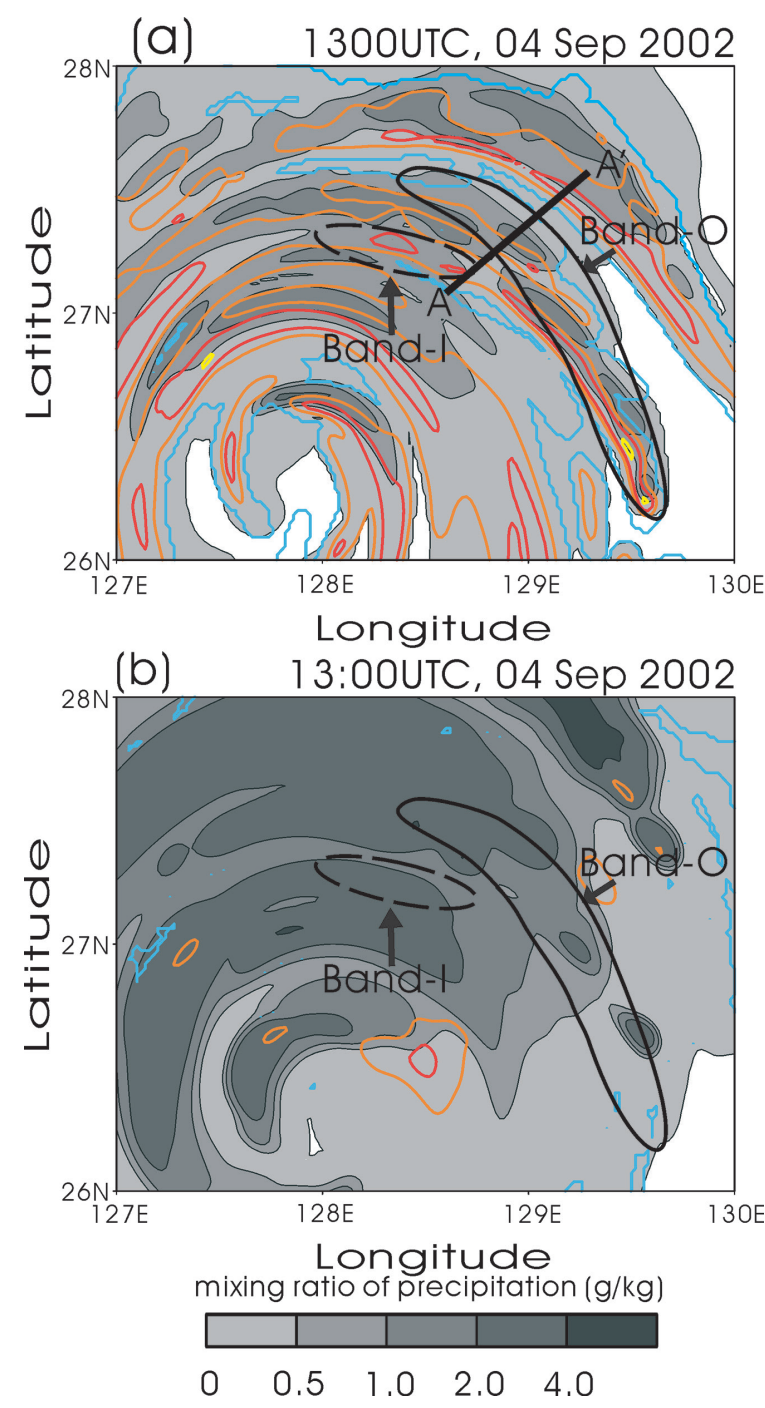

Fig. 5. Distribution of cloud and precipitation at heights of (a) $2 \mathrm{~km}$ and (b) $7 \mathrm{~km}$ at 1300 UTC. Shadings are $q_{p}$. Contours are $q_{C}$ at 0 (blue), 0.3 (orange), 0.6 (red), and 0.9 (yellow) $\mathrm{g} \mathrm{kg}^{-1}$.

fall region in Band-O, large $q_{g}$ was present. This result corresponds to the presence of graupel in the rainband documented by Heymsfield et al. (2006).

Figure 9 shows the structure of the spiral band at 1400 UTC when Band-O was in its mature stage. At heights of 2 and $7 \mathrm{~km}, q_{C}$ and $q_{p}$ in Band-I were smaller than those at 1300 UTC. The maximum $q_{p}$ in Band-O was $2.5 \mathrm{~g} \mathrm{~kg}^{-1}$. Large $q_{C}$ was present on the windward side of the large $q_{p}$ region in Band-O. Comparing $q_{C}$ and $q_{p}$ at 1400 UTC with those at 1300 UTC, the peaks of $q_{p}$ and $q_{C}$ at a height of $7 \mathrm{~km}$ increased above the 


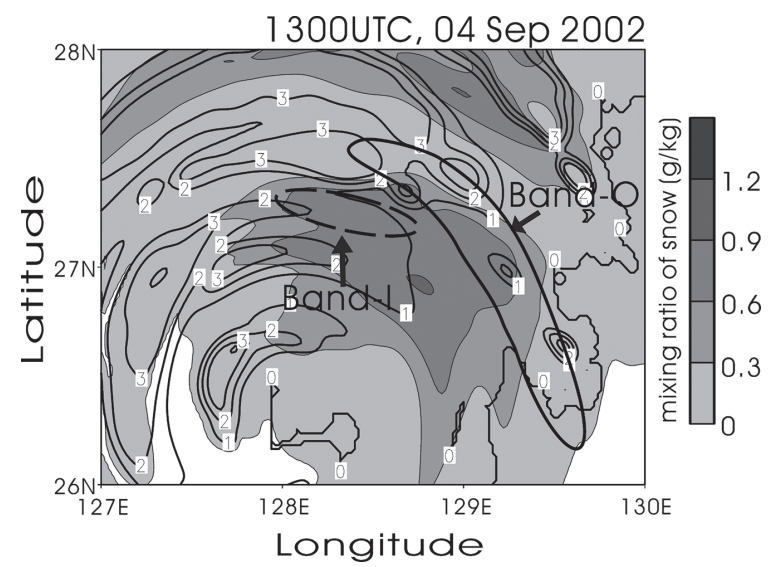

Fig. 6. Distribution of $q_{s}$ (shadings) and $q_{g}$ (contours) at a height of $7 \mathrm{~km}$. Contours are every 1.0 $\mathrm{g} \mathrm{kg}^{-1}$.

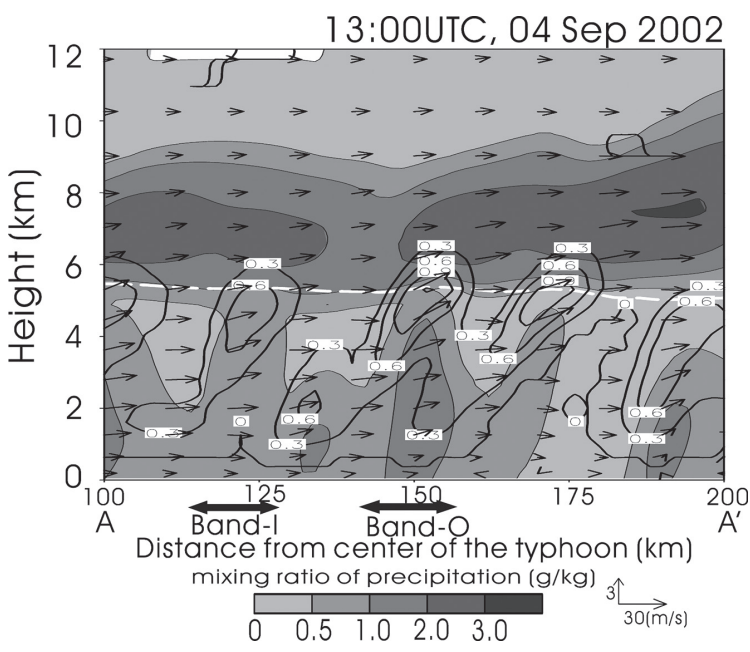

Fig. 7. Vertical cross-section of mixing ratios and storm-relative wind vectors along $\mathrm{A}-\mathrm{A}^{\prime}$ in Fig. 5 at 1300 UTC. Shadings are $q_{p}$. Contours are $q_{C}$ every $0.3 \mathrm{~g} \mathrm{~kg}^{-1}$. The dashed white line indicates the $0^{\circ} \mathrm{C}$ level. Storm-relative wind vectors are calculated by subtraction of the typhoon motion vector from the horizontal wind vector at this time.

region in which $q_{p}$ increased at a height of $2 \mathrm{~km}$ (Figs. $5 \mathrm{~b}, 9 \mathrm{~b})$. When strong rainfall occurred in the spiral band, large $q_{C}$ was present above the $0^{\circ} \mathrm{C}$ level.

$q_{s}$ in Band-I was unchanged from 1300 UTC; however, $q_{g}$ decreased (Fig. 10). In Band-O, large $q_{g}$ was present. In particular, graupel concentrated above

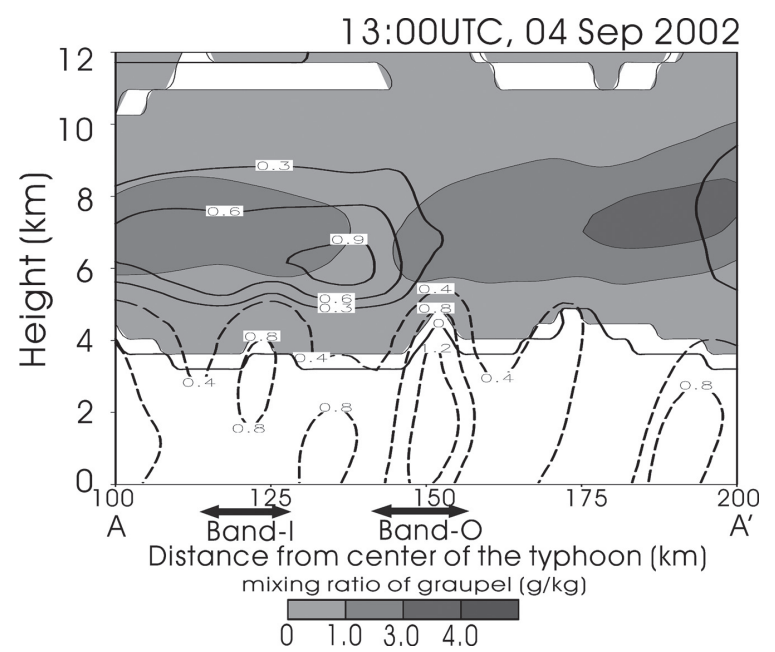

Fig. 8. Vertical cross-section of mixing ratios of precipitation along A-A' in Fig. 5 at 1300 UTC. Shadings are $q_{g}$. Solid contours are $q_{s}$ every 0.3 $\mathrm{g} \mathrm{kg}^{-1}$. Dashed lines are $q_{r}$ every $0.4 \mathrm{~g} \mathrm{~kg}^{-1}$.

the strong rainfall region in which $q_{p}$ was larger than $2.0 \mathrm{~g} \mathrm{~kg}^{-1}$ (Fig. 9a). Large $q_{s}$ was present between Band- $\mathrm{I}$ and Band-O; however, $q_{g}$ between the two spiral bands was less than that in the spiral band.

The peaks of $q_{p}$ above and below the $0{ }^{\circ} \mathrm{C}$ level in Band-O appeared to be more obvious than those at 1300 UTC (Figs. 7, 11). In Band-O, the updraft was strong around the $0{ }^{\circ} \mathrm{C}$ level, and $q_{C}$ was larger than that at 1300 UTC. Rainfall in Band-O was stronger than that at 1300 UTC. $q_{p}$ in Band-O was $1.0 \mathrm{~g} \mathrm{~kg}^{-1}$, which was larger than that in other bands. In addition, $q_{C}$ was larger than that in Band-I. There was little change in $q_{p}$ in Band-I at 1300 UTC and 1400 UTC. Therefore, it is suggested that the cold rain process had a major effect on the strong rainfall in the spiral bands.

A comparison of the maximum $q_{p}$ in Band-O at a height of $2 \mathrm{~km}$ at 1300 UTC and 1400 UTC revealed that the mixing ratio of $1.2 \mathrm{~g} \mathrm{~kg}^{-1}$ at 1300 UTC increased to $2.5 \mathrm{~g} \mathrm{~kg}^{-1}$ at $1400 \mathrm{UTC}$ (Figs. 5, 9). At a height of $7 \mathrm{~km}$, the maximum $q_{p}$ changed only by approximately $0.5 \mathrm{~g} \mathrm{~kg}^{-1}$. Comparing vertical cross-sections, $q_{p}$ above the strong rainfall region increased above the $0^{\circ} \mathrm{C}$ level (Figs. 7, 11). The distribution and amount of $q_{C}$ and $q_{p}$ above this level showed insignificant differences between the developing and mature stages. In Band- $-q_{g}$ of $3.0 \mathrm{~g} \mathrm{~kg}^{-1}$ at 1300 UTC increased to 5.0 $\mathrm{g} \mathrm{kg}^{-1}$ at 1400 UTC (Figs. 8, 12). There was very small difference between $q_{s}$ at $1300 \mathrm{UTC}$ and $1400 \mathrm{UTC}$ (Figs. 6, 10). In contrast, $q_{p}$ in Band-I hardly changed 

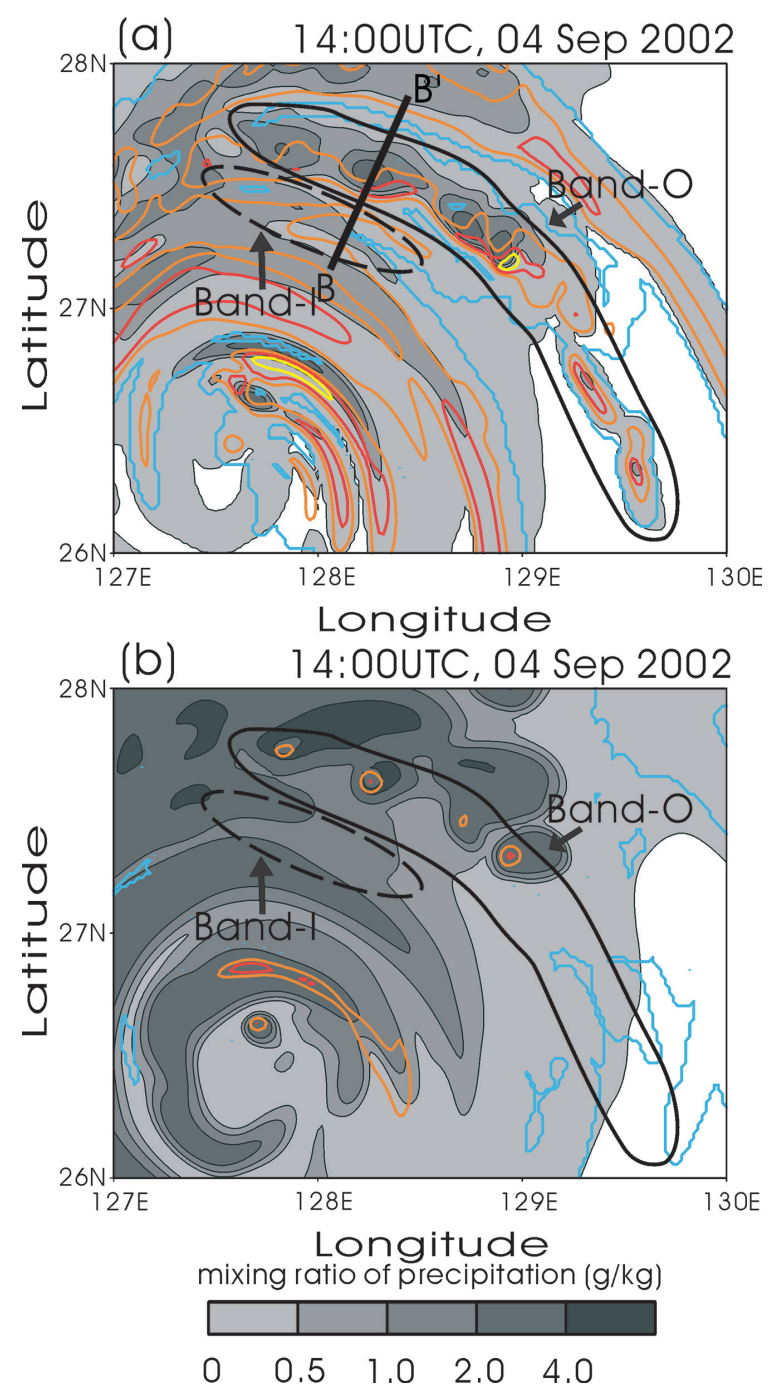

Fig. 9. Same as Fig. 5, but for 1400 UTC.

from 1300 UTC to 1400 UTC because $q_{C}, q_{s}$, and $q_{g}$ increased little above the $0^{\circ} \mathrm{C}$ level. Therefore, rainfall was intensified in the spiral band with an increase of $q_{g}$ above the $0^{\circ} \mathrm{C}$ level.

To reveal the process of graupel production and the mechanism of intensification of precipitation in the spiral band, the cloud microphysical processes were examined. We show the production and growth processes of precipitation through the collision of precipitation with cloud water. In particular, we examined the collection of cloud water by rain water $\left(\mathrm{CL}_{C R}\right)$, snow $\left(\mathrm{CL}_{C S}\right)$, and graupel $\left(\mathrm{CL}_{C G}\right)$ because these processes are 1-2 orders larger than other processes for production and growth of precipitation particles

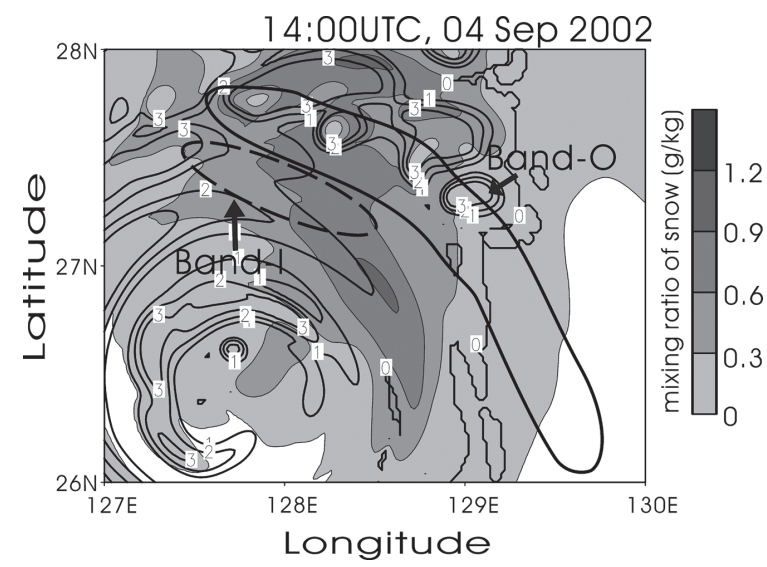

Fig. 10. Same as Fig. 6, but for 1400 UTC.

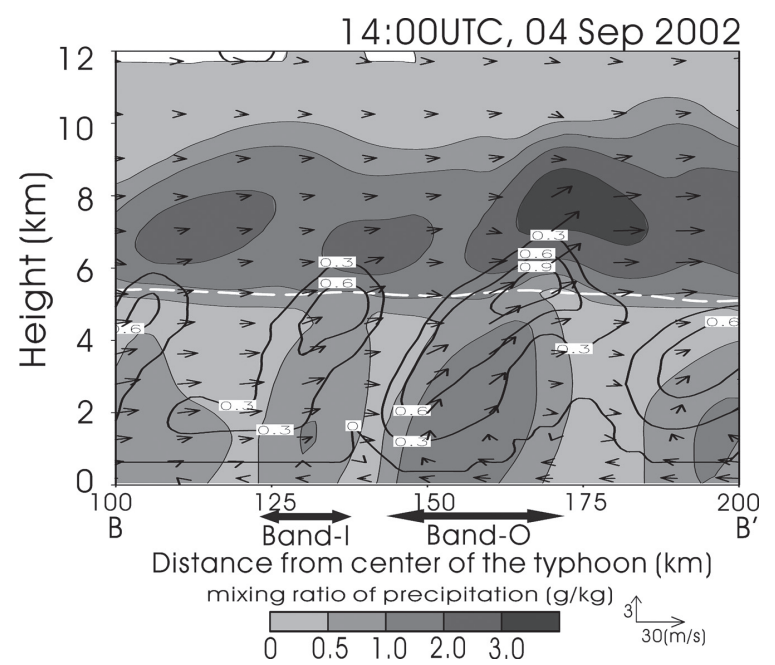

Fig. 11. Same as Fig. 7, but for B-B' in Fig. 9 at 1400 UTC.

(Fig. 13).

The three collection processes and the conversion from snow to graupel $\left(\mathrm{CN}_{S G}\right)$ at $1300 \mathrm{UTC}$ are shown in Fig. 14. $\mathrm{CL}_{C R}$ occurred mainly at the inner side of Band-O (Fig. 14a). Graupel was produced by $\mathrm{CL}_{C S}$ and $\mathrm{CN}_{S G}$ at the inner side of Band-O (Figs. 14b, c). $\mathrm{CL}_{C G}$ occurred around the axis or at the outer side of Band-O (Fig. 14d). $\mathrm{CL}_{C R}$ was larger than other processes in Band-O.

When Band-O reached its mature stage at 1400 UTC, the vertical cross-sections of the three collection processes and $\mathrm{CN}_{S G}$ along B-B' of Fig. 9a are illustrated in Fig. 15. $\mathrm{CL}_{C R}$ and $\mathrm{CL}_{C G}$ were large in Band-O. $\mathrm{CL}_{C S}$ 


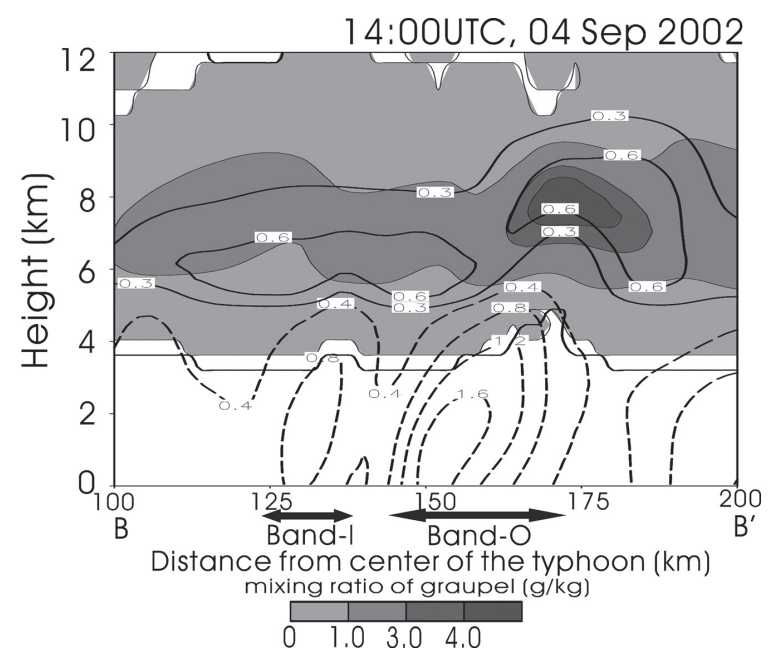

Fig. 12. Same as Fig. 8, but for B-B' in Fig. 9 at 1400 UTC.

on the inner side of the Band-O axis was larger than that on its outer side, although $q_{s}$ on the inner side of the Band-O axis was similar to that on its outer side (Figs. $12,15 \mathrm{~b})$. On the other hand, $q_{c}$ on the inner side of the axis was larger than that on the outer side (Fig. 11). As a result, $q_{c}$ collected by snow combined with $q_{s}$ on the inner side of the Band-O axis (Fig. 13). An amount of $\mathrm{CN}_{S G}$ was decided by the increase in $q_{s}$. In particular, the amount of $\mathrm{CL}_{C S}$ is an important factor deciding the amount of $\mathrm{CN}_{S G}$. A considerable amount of snow was converted to graupel on the inner side of the Band-O axis (Fig. 15c). In Band-O shown in Fig. 15, the peaks of $\mathrm{CL}_{C S}$ and $\mathrm{CN}_{S G}$ are located in the lower layer of the peak of $\mathrm{CL}_{C G}$. This result suggests that graupel was produced in the lower layer of the peak of $\mathrm{CL}_{C G}$. Therefore, snow in this layer grew and was transported to a higher layer by the updraft in Band-O. In Fig. 11, $q_{c}$ on the inner side of the band axis was larger than that on the outer side, and $\mathrm{CL}_{C S}$ on the inner side was larger than that on the outer side. Thus, for $\mathrm{CN}_{S G}$, a significant amount of cloud water should be located above the $0^{\circ} \mathrm{C}$ level. A comparison of the amount of $\mathrm{CL}_{C S}$ and $\mathrm{CN}_{S G}$ in Band-O with those in Band-I showed similar results. On the other hand, $\mathrm{CL}_{C G}$ in Band-O was $6.0 \times$ $10^{-2} \mathrm{~g} \mathrm{~kg}^{-1} \mathrm{~s}^{-1}$, which was three times as large as that in Band-I. Comparing the amount of cloud water in the bands above the $0^{\circ} \mathrm{C}$ level, $q_{c}$ in Band-I was smaller than that in Band-O (Fig. 11). This result shows that $q_{c}$ in Band-I was not sufficient for $\mathrm{CL}_{C G}$ because $\mathrm{CL}_{C S}$ consumed cloud water above the $0^{\circ} \mathrm{C}$ level. Therefore, the intensification of precipitation in the spiral band

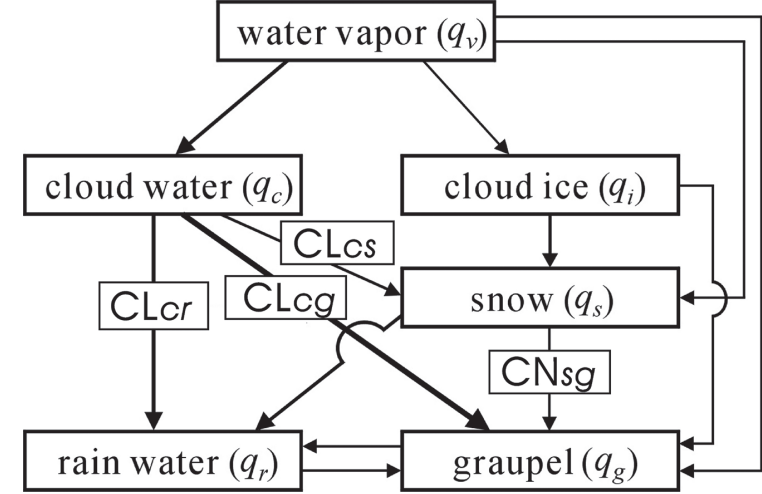

Fig. 13. Diagram of important parts of the cloud microphysical process in CReSS. $\mathrm{CL}_{C R}$ represents collection of cloud water by rain water; CLCS is collection of cloud water by snow; and $\mathrm{CL}_{C G}$ is collection of cloud water by graupel. $\mathrm{CN}_{S G}$ represents conversion from snow to graupel.

requires a significant amount of cloud water to be present above the $0^{\circ} \mathrm{C}$ level.

To show the most effective process for the intensification of precipitation in the spiral band, we compared the cloud microphysical processes at 1300 UTC with those at 1400 UTC. $\mathrm{CL}_{C R}$ and $\mathrm{CL}_{C S}$ increased by 1.0 $\times 10^{-3} \mathrm{~g} \mathrm{~kg}^{-1} \mathrm{~s}^{-1}$ from 1300 UTC to 1400 UTC. In contrast, $\mathrm{CL}_{C G}$ in Band-O increased by $3.0 \times 10^{-2}$ $\mathrm{g} \mathrm{kg}^{-1} \mathrm{~s}^{-1}$ from $1300 \mathrm{UTC}$ to 1400 UTC. Therefore, $\mathrm{CL}_{C G}$ is the principal process for intensification of precipitation in the spiral band.

\section{Transportation of cloud water and snow}

We clarified in Section 3 that the most effective process of intensifying precipitation in Band-O is the production and growth of graupel. The sources of snow and cloud water, which were necessary for the production and growth of graupel in Band-O, are examined in this section. In this experiment, large $q_{s}$ was present between Band-I and Band-O at 1300 UTC, when Band-O was in its developing stage (Fig. 6). The conversion from cloud ice to snow $\left(\mathrm{CN}_{I S}\right)$ was little between the spiral bands (Fig. 16). This result suggests that snow was generated in another region and was transported. In order to clarify the sources of snow and cloud water, we used a backward trajectory technique, which is a modification of the Golding (1984) method. The backward trajectory analysis was performed using the following algorithm: 

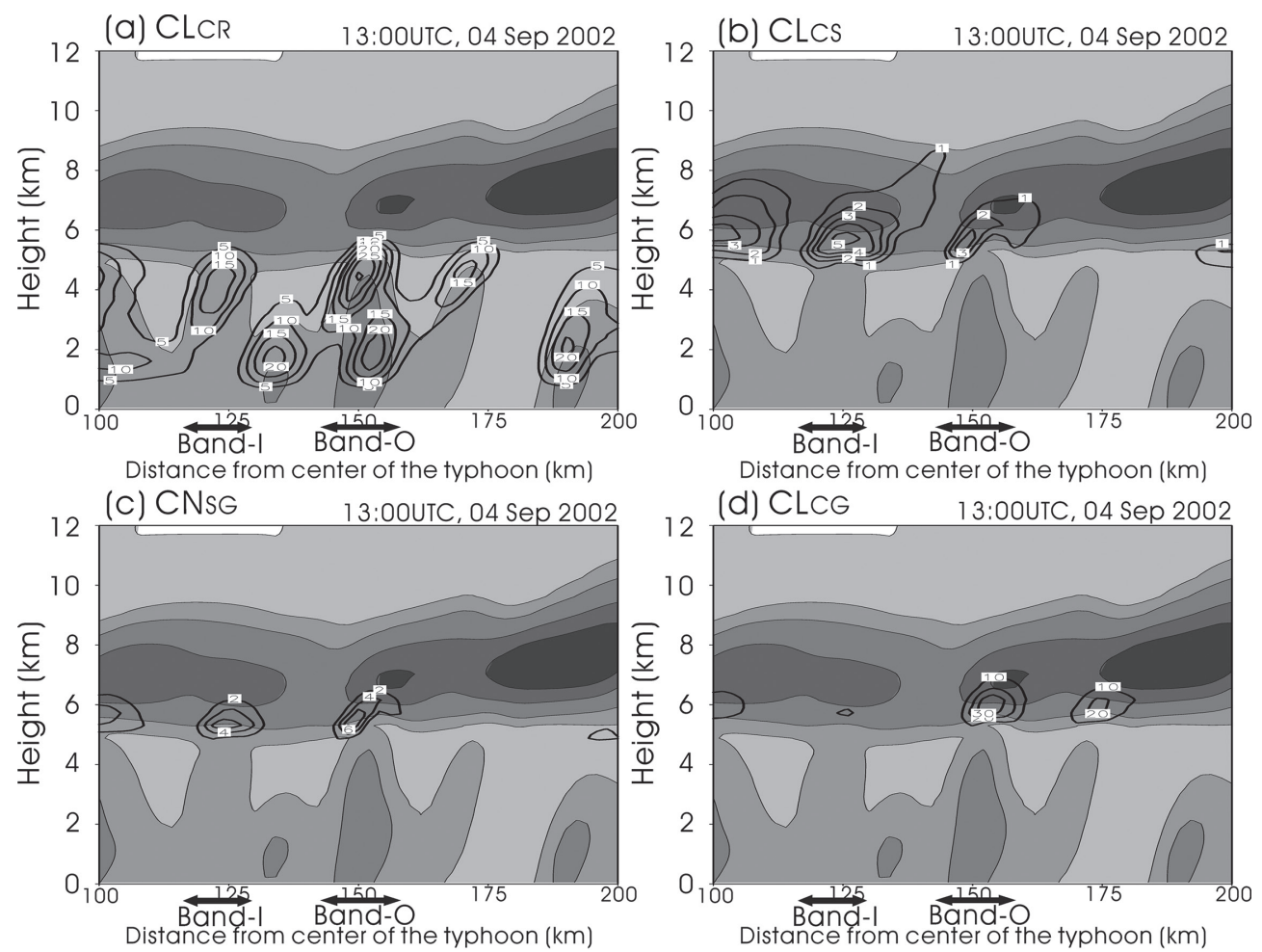

(d) CLCG

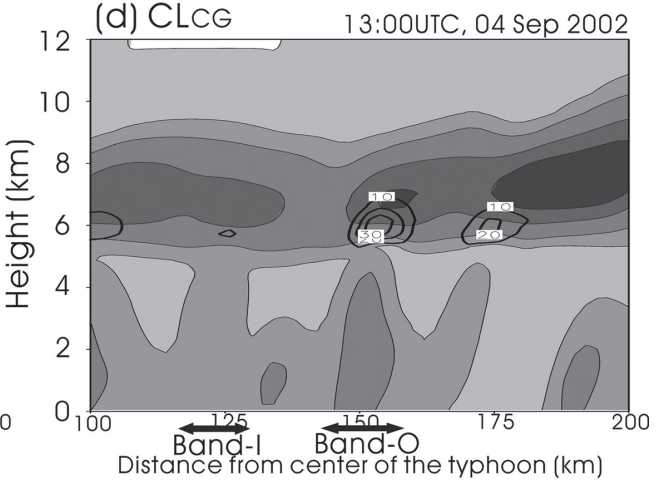

mixing ratio of precipitation $(\mathrm{g} / \mathrm{kg})$

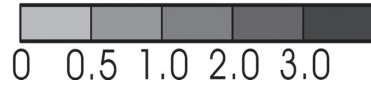

Fig. 14. Vertical cross-section of cloud microphysical processes along A-A' in Fig. 5 at 1300 UTC. Shadings are $q_{p}$. (a) $\mathrm{CL}_{C R}$ every $5.0 \times 10^{-3} \mathrm{~g} \mathrm{~kg}^{-1} \mathrm{~s}^{-1}$; (b) CL $C S$ every $1.0 \times 10^{-3} \mathrm{~g} \mathrm{~kg}^{-1} \mathrm{~s}^{-1}$; (c) $\mathrm{CN}_{S G}$ every $2.0 \times 10^{-3} \mathrm{~g} \mathrm{~kg}^{-1}$ $\mathrm{s}^{-1}$; and (d) CLCG every $1.0 \times 10^{-2} \mathrm{~g} \mathrm{~kg}^{-1} \mathrm{~s}^{-1}$.

$$
\begin{aligned}
& x^{n-\frac{1}{2}}=x^{n}-\left[u^{n}\left(x^{n}\right)+\text { Fall }_{q s}^{n}\right] * \Delta t / 2 \\
& x^{n-1}=x^{n}-\left[u^{n-\frac{1}{2}}\left(x^{n-\frac{1}{2}}\right)+\text { Fall }_{q s}^{n-\frac{1}{2}}\right] * \Delta t,
\end{aligned}
$$

where $\boldsymbol{x}$ is the position of snow and cloud water, $\boldsymbol{u}(\boldsymbol{x})$ is the interpolated velocity at position $\boldsymbol{x}$, and $\boldsymbol{n}$ is the time level. Fall. $\boldsymbol{q}_{s}$ is the source term due to the sedimentation of snow and is used only for the analysis of snow tracking. When the tracks of cloud water are solved, Fall.q $\boldsymbol{q}_{s}$ is zero. For the backward trajectory analysis, the CReSS-2km output at 5 minutes intervals from 1400 UTC to 1200 UTC was used. The backward trajectories of snow and cloud water originated at the inner edge of Band-O, where $\mathrm{CL}_{C S}$ and $\mathrm{CN}_{S G}$ were considerably large. Their vertical positions were at heights of 5.7 (squares), 6.1 (circles), and $6.5 \mathrm{~km}$ (triangles), as shown in Fig. 17.
The particles of cloud water were classified into three types of tracking measures: C1, C2, and C3 (Fig. 17a). $\mathrm{C} 1$ remained in Band-O during the analysis period and sloped at an approximate height of $3 \mathrm{~km}$ from 1200 UTC to 1400 UTC. The strong updraft generated by convergence at the inner edge of Band-O below a height of $2 \mathrm{~km}$ vertically transported $\mathrm{C} 1$ (Figs. 7, 11). In addition, $\mathrm{C} 1$ was moved along Band-O by the spiral wind (Fig. 4). C2 was located at the same position and height as $\mathrm{C} 1$ at $1300 \mathrm{UTC}$, and traced back to between Band-I and Band-O from 1300 UTC to 1200 UTC. The vertical motion from 1300 UTC to 1200 UTC was smaller than that from 1400 UTC to 1300 UTC because the updraft between the spiral bands was smaller than that in the spiral bands (Figs. 7, 11). C3 was distributed between Band-I and Band-O at 1300 UTC and traced back to Band-I at 1200 UTC. The vertical motion of $\mathrm{C} 3$ was small throughout the 2 hour period.

Between Band-I and Band-O, weak vertical wind 

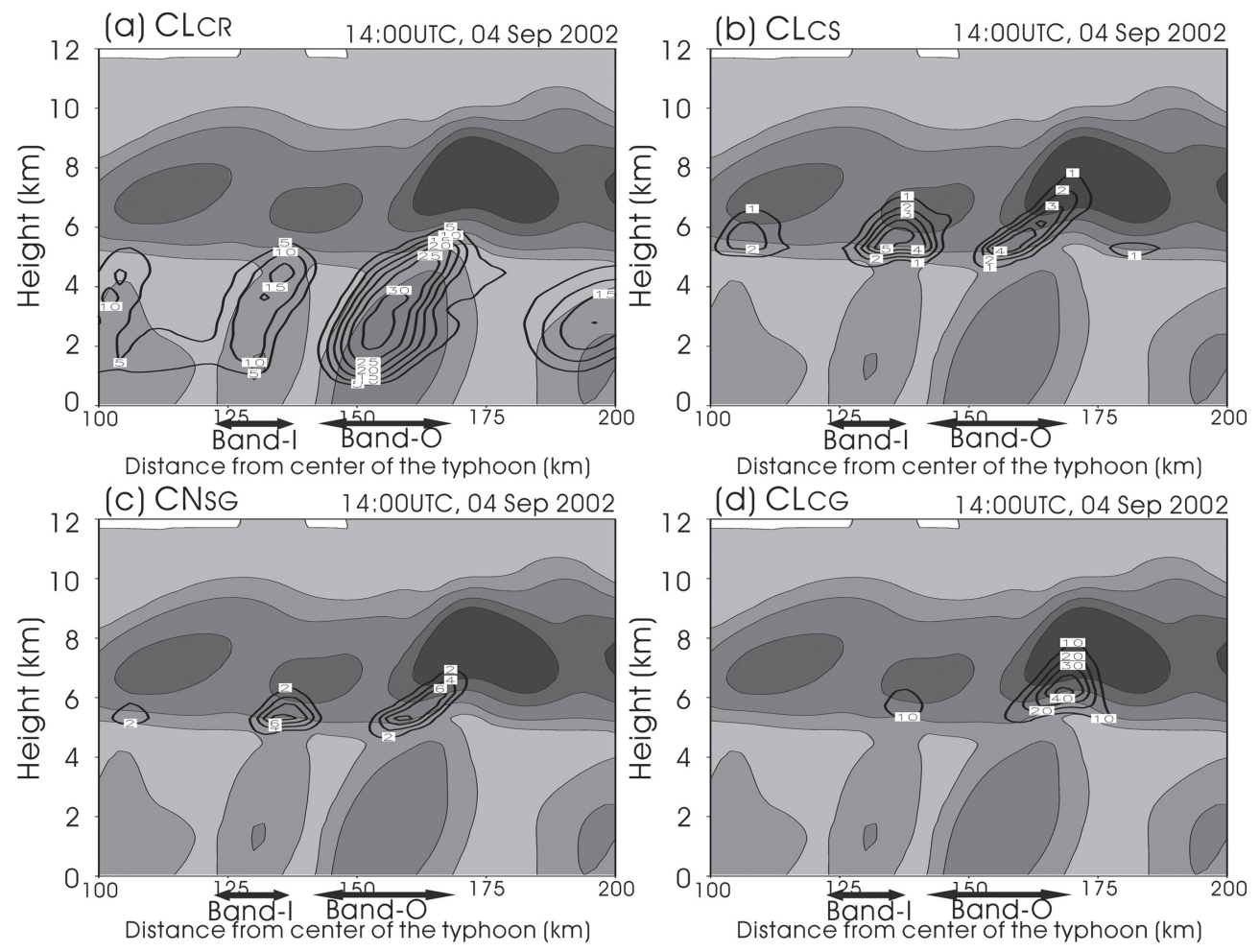

mixing ratio of precipitation $(\mathrm{g} / \mathrm{kg})$

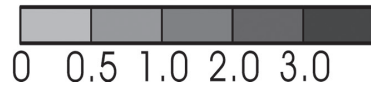

Fig. 15. Same as Fig. 14, but B-B' in Fig. 9 at 1400 UTC.

resulted in small vertical displacements of $\mathrm{C} 2$ and $\mathrm{C} 3$, which were advected from the inner edge of Band-O below the $0^{\circ} \mathrm{C}$ level. The movement of $\mathrm{C} 2$ and $\mathrm{C} 3$ was mainly horizontal between the spiral bands and vertical within the spiral bands. A large amount of water vapor was converted to cloud water $\left(\mathrm{CN}_{V C}\right)$ while water vapor was advected to Band- $\mathrm{O}$ and sloped in Band-O from 1200 UTC to 1400 UTC (Fig. 18). In addition, an amount of cloud water was hardly distributed between the spiral bands (Figs. 7, 11). These results indicate that the particles were primarily transported from Band-I to Band- $\mathrm{O}$ in the state of water vapor and converted to cloud water after reaching Band-O. At 1200 UTC and 1300 UTC, which is the developing stage of Band-O, the peak of $\mathrm{CN}_{V C}$ moved near the $0^{\circ} \mathrm{C}$ level which was at an approximate height of $5.4 \mathrm{~km}$ (Figs. 18a-d). In the mature stage, the peak of $\mathrm{CN}_{V C}$ was simulated above this level (Figs. 18e, $\mathrm{f}$ ). This transition is similar to the track of the trajectory and the peak of $q_{c}$ (Figs. $7,11,17 \mathrm{a}, 18)$. Thus, the influences of the updraft in
Band-O and the horizontal advection into its inner edge provided a large amount of cloud water for the production and growth of graupel.

All the particles of snow traced back from Band-O to Band-I (Fig. 17b). At 1300 UTC, the particles were located around the outer edge of Band-I at heights of $7-8 \mathrm{~km} . q_{s}$ was large around the outer edge of Band-I (Fig. 8). At 1200 UTC, all the particles were in Band; some particles were above the strong rainfall region in Band-I (not shown). Snow was generated mainly above the strong rainfall region in the spiral band (Fig. 16). In contrast, snow was hardly generated between Band-I and Band-O. Particles were present near the region in which a large amount of snow was generated at 1200 UTC and 1300 UTC. Therefore, snow advected to Band-O was generated in Band-I and was transported by outflow above the $0^{\circ} \mathrm{C}$ level. Snow generated in Band-I was a seed of graupel generated in Band-O. 


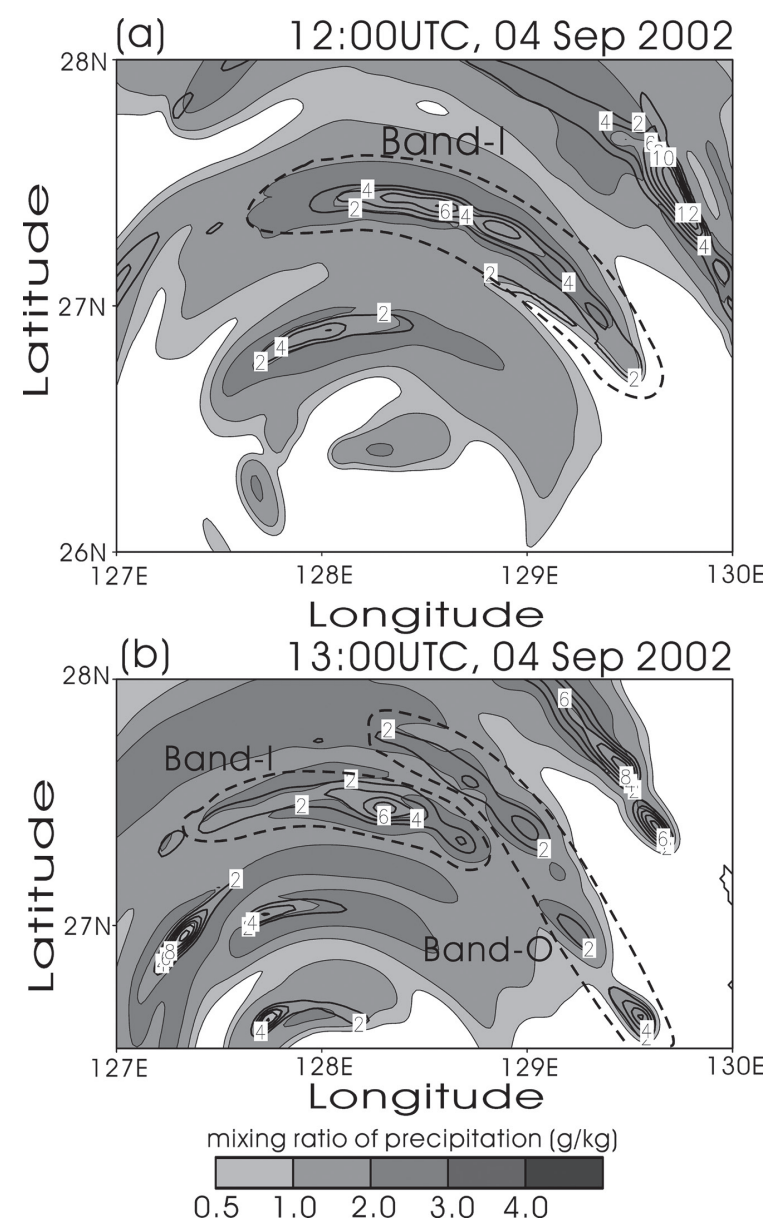

Fig. 16. Vertically integrated $\mathrm{CN}_{I S}$ at (a) 1200 UTC and (b) 1300 UTC. Shadings are $q_{p}$ at a height of $6 \mathrm{~km}$. Contours are vertically integrated $\mathrm{CN}_{I S}$ every $2.0 \times 10^{-2} \mathrm{~g} \mathrm{~kg}^{-1} \mathrm{~s}^{-1}$.

\section{Discussion}

Typhoon-scale structures of spiral bands were accurately reproduced through high-resolution simulation (Figs. 1, 3). The width of the spiral bands, strong rainfall region, and precipitation intensity were simulated in CReSS-2 km.

In this study, we revealed that strong rainfall in the spiral band was caused by large $q_{g}$ above the $0^{\circ} \mathrm{C}$ level. On 4 September 2002, the Tropical Rainfall Measuring Mission (TRMM) satellite observed Typhoon SINLAKU only once at 0705 UTC. Large amounts of liquid cloud and solid precipitation were observed in the developed spiral band above the $0^{\circ} \mathrm{C}$ level. However, Band- $-\mathrm{I}$ and Band-O did not form during
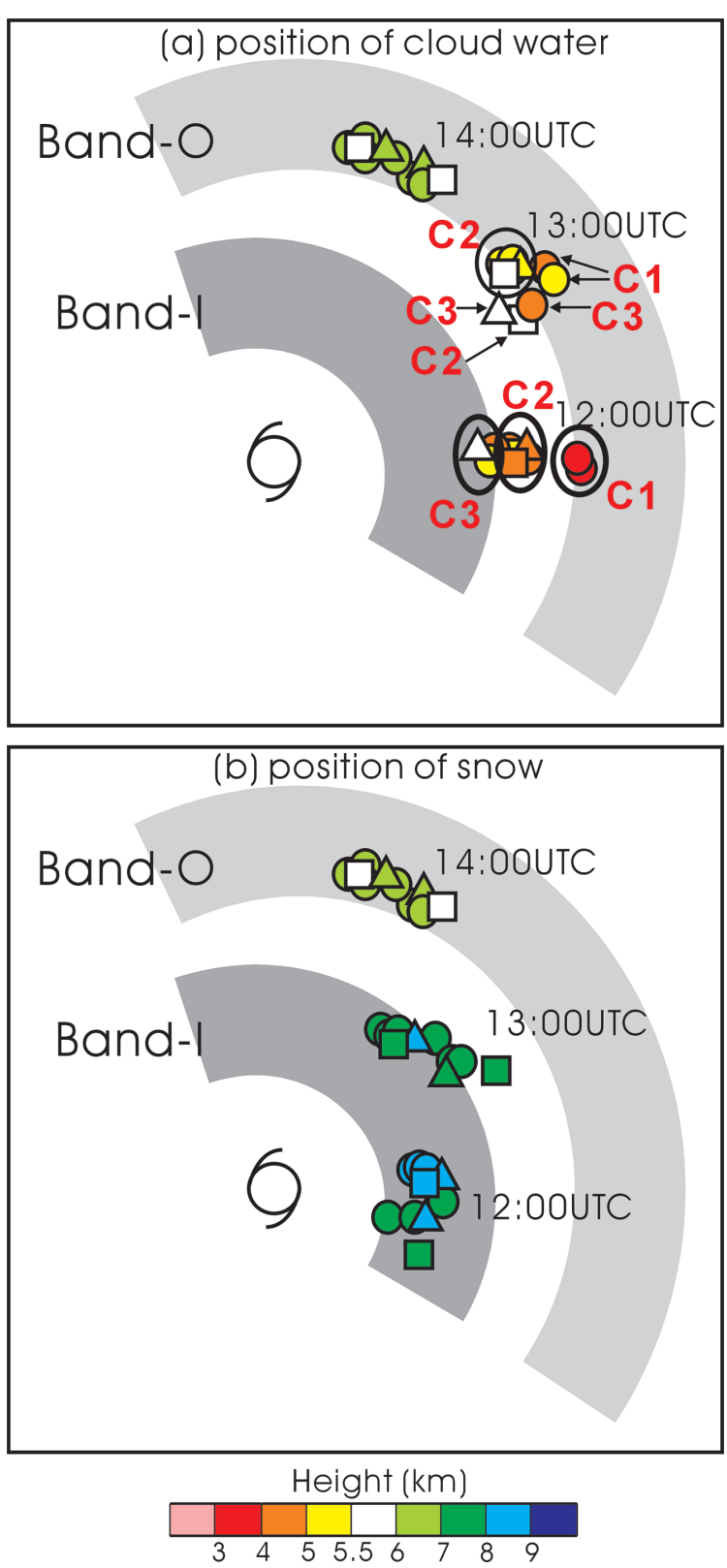

Fig. 17. Position of (a) water vapor and cloud water particles and (b) snow particles relative to the typhoon center at 1200 UTC, 1300 UTC, and 1400 UTC. The shapes differentiate heights at 1400 UTC. Squares represent height of $5.7 \mathrm{~km}$; circles are $6.1 \mathrm{~km}$; and triangles are $6.5 \mathrm{~km}$. Color levels indicate heights at each interval. 

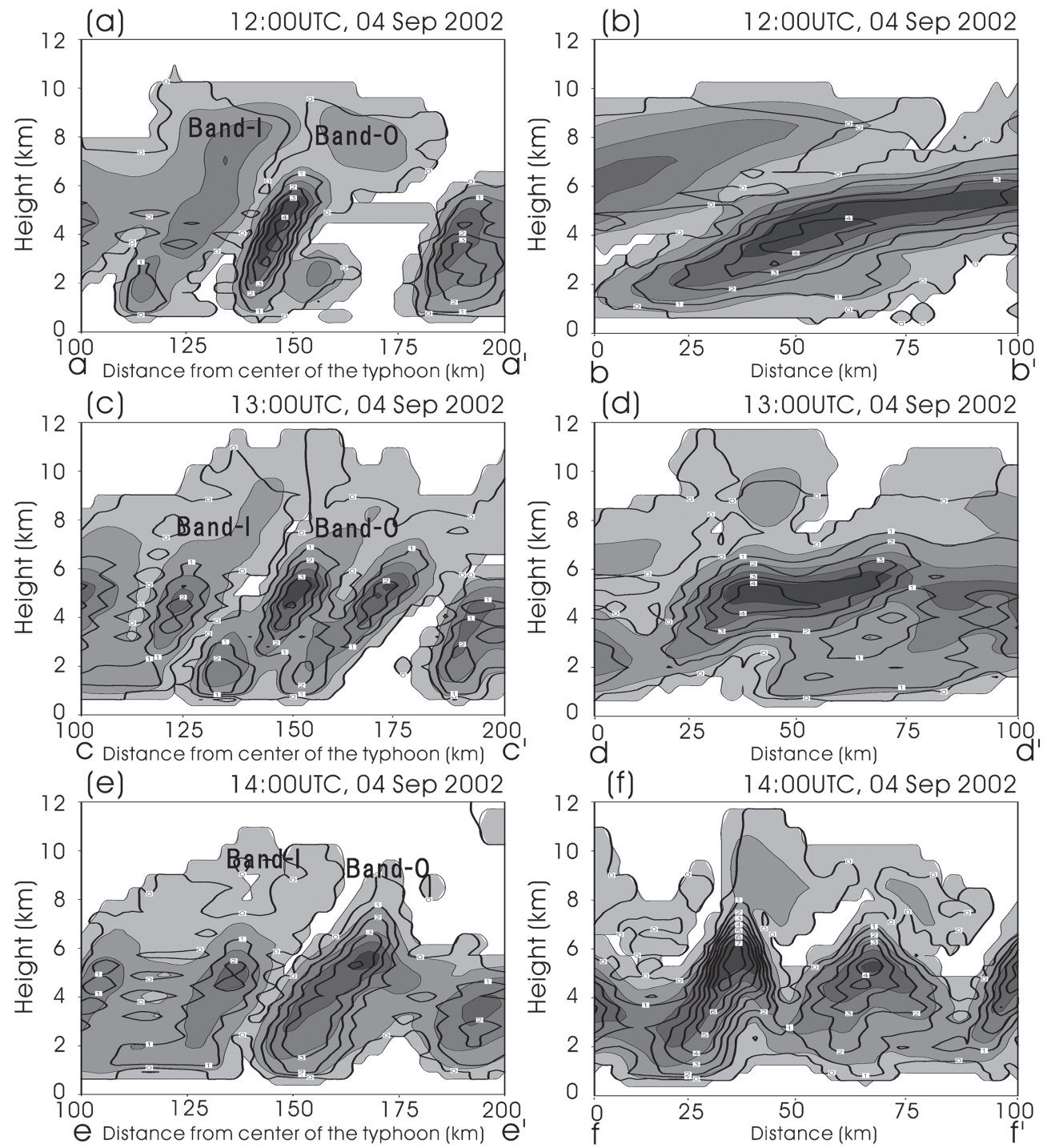

mixing ratio of cloud $(\mathrm{g} / \mathrm{kg})$

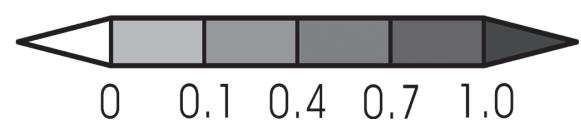

Fig. 18. Vertical cross-section of $\mathrm{CN}_{V C}$ along (a) a-a', (b) b-b', (c) c-c', (d) d-d', (e) e-e', and (f) f-f' in Fig. 4 at 1200,1300 , and 1400 UTC. Shadings are $q_{c}$. Contours indicate $\mathrm{CN}_{V C}$ every $1.0 \times 10^{-2} \mathrm{~g} \mathrm{~kg}^{-1} \mathrm{~s}^{-1}$.

this time. We believe that the distribution of cloud and precipitation in Band- $\mathrm{I}$ and Band-O is similar to that observed by the TRMM satellite. Nomura et al. (2002) compared the intensifying precipitation in the typhoon spiral band using the cold rain parameterization (EXP-C) with that using only a warm rain process $(\mathrm{EXP}-\mathrm{W})$. They showed that the rainfall in EXP-C was stronger than that in EXP-W. In EXP-W, large $q_{c}$ appeared in the upper troposphere because there was little collection of cloud water by precipitation particles above the $0^{\circ} \mathrm{C}$ level. They suggested that the cold rain process was the major process for the intensification of precipitation in the spiral band.

At $1300 \mathrm{UTC}, \mathrm{CL}_{C S}$ and $\mathrm{CN}_{S G}$ in Band-I were similar to those in Band-O (Figs. 14b, c). However, the rainfall in Band-I was weaker than that in Band-O 


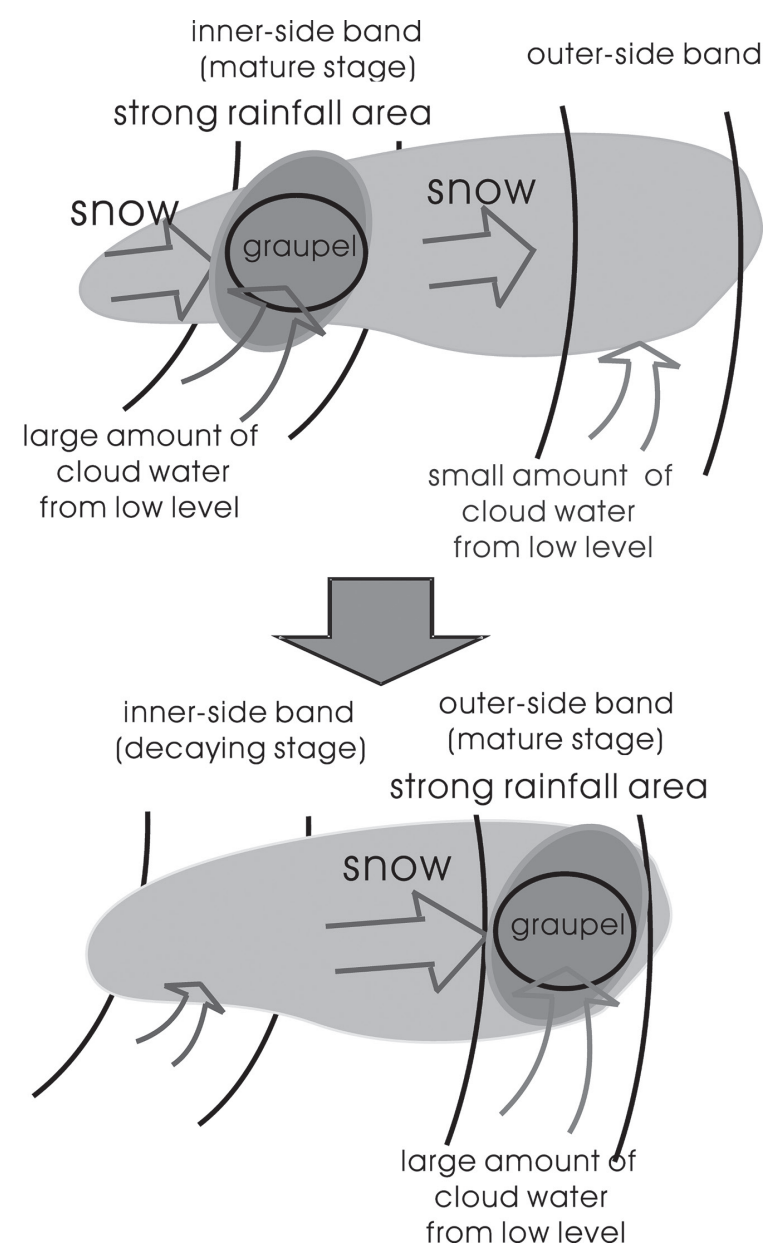

Fig. 19. Conceptual model of the mechanism for intensifying rainfall in the outer spiral band.

because $\mathrm{CL}_{C G}$ in Band-I was considerably smaller. A comparison of the region where $\mathrm{CL}_{C S}$ and $\mathrm{CN}_{S G}$ occurred in Band- $\mathrm{I}$ with that in Band-O revealed that $\mathrm{CL}_{C S}$ and $\mathrm{CN}_{S G}$ in Band-O were distributed on the inner side of the band axis. In Band-I, $\mathrm{CL}_{C S}$ and $\mathrm{CN}_{S G}$ were simulated widely in the band because large $q_{s}$ was widely distributed in the band (Fig. 8). A large amount of snow was generated in Band-I because $\mathrm{CN}_{I S}$ occurred around the spiral band axis (Fig. 16). Most of the cloud water was used for $\mathrm{CL}_{C S}$ and $\mathrm{CN}_{S G}$ above the $0{ }^{\circ} \mathrm{C}$ level in Band-I. Therefore, in Band-I, the mixing ratio of cloud water above the $0{ }^{\circ} \mathrm{C}$ level was not sufficient for the production and growth of graupel.

On the other hand, in Band-O, large $q_{c}$ was present above the $0{ }^{\circ} \mathrm{C}$ level at $1300 \mathrm{UTC}$ (Fig. 7). $\mathrm{CN}_{S G}$ and $\mathrm{CL}_{C G}$ in Band-O were larger than those in Band-I (Fig. 14). The distribution and production of large graupel in the developed rainband is in accordance with Heymsfield et al. (2006). At 1400 UTC, more cloud water was provided above the $0^{\circ} \mathrm{C}$ level in Band-O (Fig. 11) and $\mathrm{CL}_{C G}$ became considerably large (Fig. 15). In addition, large $\mathrm{CL}_{C S}$ and $\mathrm{CN}_{S G}$ occurred at higher levels than those at 1300 UTC because more $q_{c}$ was present at those levels. For large $\mathrm{CL}_{C G}$, the presence of a large amount of cloud water is essential in the spiral band above the $0^{\circ} \mathrm{C}$ level.

For the production of cloud water in Band-O, large amounts of water vapor and cloud water were advected from Band-I or from the vicinity of the typhoon center to Band-O. High humidity was present between the spiral bands near the typhoon center. Water vapor was not only transported from the low levels by the updraft but also advected from Band-I. Water vapor was a significant source for the production of large amounts of cloud water in Band-O.

Above the $0^{\circ} \mathrm{C}$ level, a large amount of snow was generated in Band-I and it increased before the development of Band-O (Figs. 14b, 16). Snow was widely distributed in Band-I and between the spiral bands at 1300 UTC (Figs. 6, 8). Moreover, snow was transported from Band-I to the region between Band-I and Band-O by the mid-level outflow before it converted to graupel or fell below the $0^{\circ} \mathrm{C}$ level because the terminal velocity of snow is lower than that of graupel. The distribution of snow simulated between the spiral bands is in accordance with Black and Hallett (1986). Snow generated in Band-I was transported to the inner edge of Band-O by the mid-level outflow (Fig. 11). Snow was hardly generated between the spiral bands because the small amount of cloud water was present there (Figs. 5, 16). In Band-O, snow advected by the mid-level outflow acted as a seed for the generation of graupel. On the other hand, snow was generated mainly in the spiral band at the outer side of its axis. This result firmly supports that the large amount of snow that becomes the seed for the generation of graupel in Band-O is transported from Band-I.

The distribution of cloud and precipitation in the inner rainband was consistent with the observations of developed hurricanes by Black and Hallett (1986) and Heymsfield et al. (2006). Although the interaction between spiral bands has been observed by Willoughby et al. (1984), May (1997), and others, it is difficult to understand the process and the mechanism of this interaction. In particular, it is very difficult to observe the cloud microphysical process in the spiral band. Using a numerical model, we clarified the cloud microphysical process in the inner rainband and the mechanism of the intensification of precipitation in Band-O that is 
influenced by Band-I.

\section{Summary}

Simulation of a typhoon with fine mesh resolution was performed using a non-hydrostatic cloudresolving model. The results provided a basis for the examination of detailed cloud microphysical processes and the influence from the inner-side band to the outer-side neighboring band on the intensification of precipitation in the spiral band.

A large amount of precipitation was present in the outer part of the spiral band axis, and a large amount of cloud was mainly present in the inner part of its axis. In particular, above the strong rainfall region, a large amount of cloud water was present above the $0^{\circ} \mathrm{C}$ level. Strong rainfall in the spiral band was caused by a large amount of solid precipitation particles, with graupel having a considerable impact on the intensification of precipitation.

In addition, in the spiral band, a large amount of snow advected from the inner side of the band by outflow collected cloud water and converted to graupel. This graupel grew by riming when a large amount of cloud water was available above the $0^{\circ} \mathrm{C}$ level. Moreover, the production and growth of graupel in the spiral band were the most effective processes for producing strong rainfall. These results show that the cold rain process in the spiral band is important for intensifying precipitation in the spiral band.

Figure 19 is a conceptual model of the mechanism for intensified rainfall in the outer-side spiral band when two spiral bands near the typhoon center are located within a few tens of kilometers. The amount of cloud water above the $0^{\circ} \mathrm{C}$ level decreases in the decaying inner-side band. The available cloud water is not sufficient for conversion from snow to graupel. However, snow increases in the inner-side band and is transported to the outer-side band by the mid-level outflow. Snow serves as a seed for a large amount of graupel in the outer-side band where the production of cloud water intensifies in the developing and mature stages. A considerable amount of cloud water is present in the outer-side band. With a large amount of cloud water from the lower level above the $0^{\circ} \mathrm{C}$ level provided by the updraft and snow advected from the inner-side band, graupel grows effectively by riming. For strong rainfall in the spiral band, the seeder-feeder mechanism occurs in its inner side edge above the $0^{\circ} \mathrm{C}$ level.

\section{Acknowledgments}

We would like to express our gratitude to Professor
H. Uyeda and Dr. T. Shinoda of Nagoya University for their valuable suggestions. We would also like to thank Dr. T. Nasuno, Research Institute for Global Change, Japan Agency for Marine-Earth Science and Technology, for her inspiring suggestions and fruitful discussions. We thank Mr. A. Sakakibara, Chuden CTI Corporation, for his help in the model setup. We appreciate the helpful comments from two anonymous reviewers which helped to improve the original manuscript. We are grateful to the Meteorological Research Institute for providing the JMA-RSM data. The numerical calculations were performed using the Earth Simulator of the Earth Simulator Center and HITACHI SR-8000 of the University of Tokyo. Figures were drawn using the Grid Analysis and Display System (GrADS).

\section{References}

Black, R. A., and J. Hallett, 1986: Observations of the distribution of ice in hurricanes. J. Atoms.Sci., 43, 802-822.

Golding, B., 1984: A study of the structure of mid-latitude depressions in a numerical model using trajectory techniques. I: Development of idea baroclinic waves in dry and moist atmospheres. Quart. J. Roy. Meteor. Soc., 110, 847-879.

Heymsfield, A. J., A. Bansemer, S. L. Durden, R. L. Herman, and T. P. Bui, 2006: Ice microphysics observations in Hurricane Humberto: Comparison with non-hurricane-generated ice cloud layers. J. Atoms. Sci., 63, 288-308.

Jorgensen, D. P., 1984: Mesoscale and convective-scale characteristics of mature hurricanes. Part I: General observations by research aircraft. J. Atmos. Sci., 41, 1268-1285.

May, P. T., 1996: The Organization of convection in the rainbands of Tropical Cyclone Laurence. Mon. Wea. Rev., 124, 807-815

Liu, Y., D. -L. Zhang, and M. K. Yau, 1997: A multiscale numerical study of Hurricane Andrew (1992). Part I: Explicit simulation and verification. Mon. Wea. Rev., 125, 3073-3093.

Nasuno, T., and M. Yamasaki, 1997: The effect of surface friction on the mesoscale organization of cumulus convection in tropical cyclones. J. Meteor. Soc. Japan, 75, 907-923.

Nasuno, T., and M. Yamasaki, 2001: A representation of cumulus-scale effects in a mesoscale-convectionresolving model for tropical cyclones. J. Meteor. Soc. Japan, 79, 1035-1057.

Nomura, M., K. Tsuboki, and T. Shinoda, 2002: Effects of the cold rain processes on the formation of typhoon spiral bands. Proceedings of International Conference on Mesoscale Convective Systems and Heavy Rainfall/ Snowfall in East Asia, 240-244. 
Powell, M. D., 1990: Boundary layer structure and dynamics in outer hurricane rainbands. Part I: Mesoscale rainfall and kinematic structure. Mon. Wea. Rev., 118, 891-917.

Senn, H. V., and H. W. Hiser, 1959: On the origin of hurricane spiral bands. J. Meteor, 16, 419-426.

Shibagaki, Y., M. D. Yamanaka, M. Kita-Fukase, H. Hashiguchi, Y. Maekawa, and S. Fukao, 2003: Meso- $\alpha$-scale wind field and precipitating clouds in Typhoon 9426 (Orchid) observed by the MU radar. J. Meteor. Soc. Japan, 81, 211-228.

Shimazu, Y., 1998: Classification of precipitation systems in mature and early weakening stages of typhoons around Japan. J. Meteor. Soc. Japan, 76, 437-445.

Simpson, R. H., and L. G. Starrrett, 1955: Further studies of hurricane structure by aircraft reconnaissance. Bull. Amer. Meteor. Soc., 36, 459-470.

Staff Members, Tokyo University, 1969: Precipitation bands of Typhoon Vera in 1959. Part I. J. Meteor. Soc. Japan, 47, 298-309.

Tsuboki, K., and A. Sakakibara, 2002: Large-scale parallel computing of cloud resolving storm simulator. High Performance Computing, Springer, 243-259.

Willoughby, H. E., F. D. Marks Jr., and R. J. Feinberg, 1984: Stationary and moving convective bands in hurricanes. J. Atmos. Sci., 41, 3189-3211.

Yamasaki, M., 1986: A three-dimensional tropical cyclone model with parameterized cumulus convection. Pap. Meteor. Geophys., 37, 205-234. 